\title{
Article
}

\section{Process Simulation Modelling of the Catalytic Hydrodeoxygenation of 4-Propylguaiacol in Microreactors}

\author{
Sanaa Hafeez ${ }^{1}\left(\mathbb{D}\right.$, Sabbir Mahmood ${ }^{2}$, Elsa Aristodemou ${ }^{1}\left(\mathbb{D}\right.$, Sultan M. Al-Salem ${ }^{3} \mathbb{D}$, George Manos ${ }^{4, *}$ (D) and \\ Achilleas Constantinou $1,5, *$
}

1 Division of Chemical \& Energy Engineering, School of Engineering, London South Bank University, London SE1 0AA, UK; hafeezs3@1sbu.ac.uk (S.H.); aristode@lsbu.ac.uk (E.A.)

2 Fluensys, Fluid and Energy Solutions Consultancy, London N1 3HS, UK; sabbirmahmood44@hotmail.com

3 Environment \& Life Sciences Research Centre, Kuwait Institute for Scientific Research, P.O. Box 24885, Safat 13109, Kuwait; ssalem@kisr.edu.kw

4 Department of Chemical Engineering, University College London, London WCIE 7JE, UK

5 Department of Chemical Engineering, Cyprus University of Technology, 57 Corner of Athinon and Anexartisias, Limassol 3036, Cyprus

* Correspondence: g.manos@ucl.ac.uk (G.M.); axilleas.constantinou@gmail.com (A.C.)

check for updates

Citation: Hafeez, S.; Mahmood, S.; Aristodemou, E.; Al-Salem, S.M.;

Manos, G.; Constantinou, A. Process Simulation Modelling of the Catalytic Hydrodeoxygenation of

4-Propylguaiacol in

Microreactors. Fuels 2021, 2, 272-285.

https://doi.org/10.3390/fuels2030016

Academic Editor: Juan

Carlos Serrano-Ruiz

Received: 17 June 2021

Accepted: 13 July 2021

Published: 16 July 2021

Publisher's Note: MDPI stays neutral with regard to jurisdictional claims in published maps and institutional affiliations.

Copyright: (c) 2021 by the authors. Licensee MDPI, Basel, Switzerland. This article is an open access article distributed under the terms and conditions of the Creative Commons Attribution (CC BY) license (https:/ / creativecommons.org/licenses/by/ $4.0 /)$.

\begin{abstract}
A process simulation model was created using Aspen Plus to investigate the hydrodeoxygenation of 4-propylguaiacol, a model component in lignin-derived pyrolysis oil, over a presulphided $\mathrm{NiMo} / \mathrm{Al}_{2} \mathrm{O}_{3}$ solid catalyst. Process simulation modelling methods were used to develop the pseudohomogeneous packed bed microreactor. The reaction was conducted at $400{ }^{\circ} \mathrm{C}$ and an operating pressure of $300 \mathrm{psig}$ with a 4-propylguaiacol liquid flow rate of $0.03 \mathrm{~mL} \cdot \mathrm{min}^{-1}$ and a hydrogen gas flow rate of $0.09 \mathrm{~mL} \cdot \mathrm{min}^{-1}$. Various operational parameters were investigated and compared to the experimental results in order to establish their effect on the conversion of 4-propylguaiacol. The parameters studied included reaction temperature, pressure, and residence time. Further changes to the simulation were made to study additional effects. In doing so, the operation of the same reactor was studied adiabatically, rather than isothermally. Moreover, different equations of state were used. It was observed that the conversion was enhanced with increasing temperature, pressure, and residence time. The results obtained demonstrated a good model validation when compared to the experimental results, thereby confirming that the model is suitable to predict the hydrodeoxygenation of pyrolysis oil.
\end{abstract}

Keywords: microreactors; 4-propylguaiacol; pyrolysis oil; hydrodeoxygenation; pseudo-homogeneous; biomass

\section{Introduction}

Pyrolysis of biomass, a renewable source, is noted to be an attractive process to produce biomass-derived fuels due to its economical and operational advantages. The operational advantages of the pyrolysis process are the requirement of no flue gas clean up, and the economic advantages of the pyrolysis process are based on the fact that many of the feedstock pre-treatment steps are not necessary when compared to other waste management processes [1]. A clean fuel may be regarded as producing lower toxic emissions, such as sulfur, when compared to conventional fossil fuels [2]. It involves the decomposition of a substance with the use of heat in the absence of oxygen [1]. Biomass feedstocks (e.g., non-food lignocellulosic) can undergo fast pyrolysis to produce fuels [3]. In fast pyrolysis processes, the biomass feedstock will decompose rapidly to produce mostly vapours and aerosols, gas, and charcoal. Following cooling and condensation, a mobile homogeneous liquid (bio-oil) can then be achieved which has a heating value of approximately 50\% of what typical fuel oils have [4,5]. Typically, the cellulose derived compounds are studied, as opposed to the lignin derived compounds; thus, there is the opportunity to explore the reaction kinetics for these lignin derived components [6]. 
The liquid bio-oil product can be further processed using hydrogen under high temperatures and pressures to remove heteroatoms such as oxygen, sulfur, and nitrogen. The hydrodeoxygenation (HDO) process is a desirable method to process oxygen containing compounds (acids, aldehydes, alcohols, and phenols) for fuels. This method is more superior to other methods, such as catalytic fast pyrolysis, in terms of lower conversion efficiencies [7]. We would like to investigate this promising process by selecting the compound 4-propylguaiacol as the foundation for investigating the HDO process in a plug flow microreactor. This is due to the fact that 4-propylguaiacol possesses similar characteristics to a few of the most important lignin-derived compounds observed in pyrolysis oil such as benzene, phenol, and guaiacol. The presence of these specific components in pyrolysis derived oil is the origin of polymerisation and coking during the HDO at higher temperatures greater than $300{ }^{\circ} \mathrm{C}$. By performing a study on the HDO of 4-propylguaiacol, a better understanding of the mechanism and kinetics for the upgrading of pyrolysis oil can be achieved $[3,8]$.

The majority of HDO studies have been investigated on an experimental basis. Shu et al. [9] researched the catalytic HDO of phenolic compounds using a highly dispersed $2 \mathrm{wt} . \% \mathrm{Ru} / \mathrm{TiO}_{2}$ catalyst. It was found that the high dispersion of the of $\mathrm{Ru}$ led to the highly efficient HDO of bio-oil. Furthermore, a 91.3\% selectivity was observed during the reaction of guaiacol to cyclohexane, under reaction conditions of temperature $260^{\circ} \mathrm{C}$ and 145 psig $\mathrm{H}_{2}$ pressure. The reaction system was also well suited to the upgrading of pyrolysis oil derived from cotton straw, and a product yield of $32.4 \%$ and $57.6 \%$ for hydrocarbons and alkylphenols, respectively, was achieved at $280^{\circ} \mathrm{C}$. In addition, the hydrocarbon yield increased to $41.4 \%$ when the reaction temperature was increased to $300^{\circ} \mathrm{C}$.

Zerva et al. [10] studied the HDO of phenol and biomass fast pyrolysis oil over $10 \%$ $\mathrm{Ni} / \mathrm{ZrO}_{2}$ and $10 \% \mathrm{Ni} / \mathrm{WO}_{3}-\mathrm{ZrO}_{2}$ catalysts. The study was performed in a fixed bed reactor under mild conditions of 435 psig $\mathrm{H}_{2}$ pressure and temperatures from $50-250{ }^{\circ} \mathrm{C}$. The results showed that the $\mathrm{Ni} / \mathrm{ZrO}_{2}$ catalyst achieved a $100 \%$ conversion and maximum selectivity at $110{ }^{\circ} \mathrm{C}$ towards cyclohexanol in the phenol $\mathrm{HDO}$ experiments. The addition of $\mathrm{WO}_{3}$ in $\mathrm{ZrO}_{2}$ provided enhanced acidity and demonstrated a total $\mathrm{HDO}$ of phenol to cyclohexane at lower reaction temperatures of $150{ }^{\circ} \mathrm{C}$. Furthermore, the $\mathrm{Ni} / \mathrm{WO}_{3}-\mathrm{ZrO}_{2}$ catalyst generated a liquid product consisting of predominantly alkyl-cycloalkanes and fewer alkyl-benzenes at reaction conditions of $210^{\circ} \mathrm{C}$ and $435 \mathrm{psig}_{2}$.

Tran et al. [11] investigated the $\mathrm{HDO}$ of bamboo derived guaiacol using $\mathrm{Ni} / \gamma-\mathrm{Al}_{2} \mathrm{O}_{3}$ and $\mathrm{Fe} /$ activated carbon (AC) catalysts. A 91.52\% conversion of guaiacol to cresol and 1,2-dimethoxybenzene was achieved under atmospheric pressure and $300{ }^{\circ} \mathrm{C}$ with the $\mathrm{Fe} / \mathrm{AC}$ catalyst. Furthermore, using constant reaction conditions, the $\mathrm{Ni} / \gamma-\mathrm{Al}_{2} \mathrm{O}_{3}$ catalyst, which was calcined at $450{ }^{\circ} \mathrm{C}$, achieved a $96.88 \%$ guaiacol conversion, producing $13.03 \%$ of cresol, $58.98 \%$ of 1,2-dimethoxybenzene, and $27.99 \%$ of 3-methyl guaiacol. The liquid products obtained using the $\mathrm{Ni} / \gamma-\mathrm{Al}_{2} \mathrm{O}_{3}$ catalyst had a wider variety of compositions when compared to the liquid products obtained with the AC catalyst. Furthermore, the Ni supported catalyst promoted the deoxygenation pathway by dehydration, as well as the demethoxylation and transalkylation reaction pathways.

In order to fully interpret the effects of the HDO process, some studies have performed mathematical modelling exercises to understand the interaction with components under different conditions. Lv et al. [12] investigated the fast pyrolysis of biomass in a dual fluidized bed reactor and the HDO of bio-oil using Aspen Plus. The results showed that if the pressure drop decreased from 4 to $1.5 \mathrm{psig}$, the total exergetic efficiency increased from $68 \%$ to $69 \%$. This suggested that the effects of pressure drop were minimal on the fast pyrolysis of biomass. Furthermore, the exergetic efficiency increased from $69 \%$ to $76 \%$ provided that the char undergoes partial combustion and matched the minimum heat required for the pyrolysis reaction. The exergy destruction is mainly present in the mild HDO units, the separation of mild HDO products and the detailed HDO. Nonetheless, this efficiency can be enhanced by recovering the excess heat from the exhaust gas. It was 
concluded that by only considering the desired product, the total exergetic efficiency of the plant is $57 \%$ and $49 \%$ via fast pyrolysis and HDO of biomass, respectively. As a result, combining the fast pyrolysis process with the subsequent HDO can be considered a highly efficient conversion process.

Bagnato et al. [13] investigated the process and techno-economic analysis based on the catalytic HDO of biomass derived fast pyrolysis oil using Aspen Plus. The results showed that, based on a processed bio-oil capacity of $10 \mathrm{Mt} / \mathrm{y}$, the resulting economic potential was found to be $38,234 \mathrm{MM} \$ / \mathrm{y}$. Furthermore, the insoluble bio-oil generated light gasoline and diesel fuel products with values of 22.22 and 18.87 \$ GJ, respectively. Additionally, the water-soluble bio-oil was further upgraded to generate 51.43 ton/day of chemicals which had an equivalent value to the market price. It was concluded that the bio-oil plant created using Aspen Plus generated a return of investment of $69.18 \%$ with a plant lifecycle of 30 years.

Shemfe et al. [14] investigated the heat integration for a bio-oil hydroprocessing plant using Aspen Plus. It was found that the optimum energy and cost performance was achieved with a steam to carbon ratio of three, as opposed to higher studied values of four and five. Furthermore, an improved economic performance can be achieved by using the waste heat from the second HDO reactor effluent to heat the feed to the first HDO reactor. This design also resulted in a lower capital cost.

Even though many of these processes are often investigated in larger conventional reactors, microreactors have gained an increasing attention recently in fuel production industries. These miniature devices are associated with high surface area to volume ratio, enhanced mass and heat transfer, and reduced residence times. In addition, microreactors allow reactions to occur under milder conditions (lower temperatures and pressures), encouraging a more green and sustainable practice when compared to larger conventional reactors [15]. Furthermore, the production capacity can be scaled up (i.e., by numbering up these devices to increase the production output) to improve the efficiency of production capacity [15-17]. Packed bed microreactors can retain very high mass and heat transfer coefficients, whilst enhancing the catalyst mass to reactor volume ratio in the reactor. Furthermore, reactor loading is easier and there is a potential for catalyst replacement [18].

The HDO of bio-oil in microreactors is often investigated on an experimental basis, so there is great potential to explore this catalytic process using mathematical modelling processes. Some studies have investigated the HDO of bio-oil using computational fluid dynamics (CFD) [8,19-21] and process simulation modelling methods using Aspen Plus (for example [12,22]). Furthermore, only a few studies have explored the HDO of 4propylguaiacol, and only a few HDO studies have been conducted in microreactors. This adds to the novelty and innovation of the current work. The current study aims to investigate the HDO reaction using Aspen Plus as the theoretical methodology. The kinetics of lignin-derived compounds from pyrolysis oil are not often studied. Therefore, the current work will enable greater understanding of the reaction kinetics and pathways regarding the upgrading of pyrolysis oil. In this study, the catalytic $\mathrm{HDO}$ of 4-propylguaiacol to 4-propylphenol has been studied in a packed bed microreactor over a $\mathrm{NiMo} / \mathrm{Al}_{2} \mathrm{O}_{3}$ catalyst. The process Simulation model was developed in Aspen Plus using Langmuir Hinshelwood Hougen Watson (LHHW) kinetics. Parametric studies were performed to assess the effects of reaction temperature, pressure, and residence time to determine their effects on the conversion of 4-propylguaiacol. The results obtained were then validated with experimental data from literature to evaluate the strength of the simulation model and can be further used to improve the performance of the microreactor.

\section{Results and Discussion}

\subsection{Effects of Temperature}

The modelling results generated by Aspen Plus were compared to those from the available literature. This was done to validate the model and determine the accuracy of the predicted theoretical results. The model was compared with the experimental 
results for a microreactor operating under 300 psig and between 250 and $450{ }^{\circ} \mathrm{C}$. The experimental work found that the conversion of 4-propylguaiacol had an error of $+/-$ $5 \%$. The process modelling results were compared to CFD results from our previously published study [8]. The current Aspen-based model is a simple pseudo homogeneous model, where the catalyst bed and fluid phases are treated as one phase. On the other hand, CFD enabled us to develop a more sophisticated heterogeneous model [8], where model equations were applied separately to the catalyst bed and the reaction mixture component phases. Figure 1 shows the comparison between the results obtained experimentally and the results predicted by the process simulation model and CFD model. The simulation model aligns well with the experimental data for a reactor temperature below $400{ }^{\circ} \mathrm{C}$. The results demonstrate that the conversion increases in a proportional manner when the temperature is increased. The CFD results also show a sound validation, with the process simulation results demonstrating good validity. Therefore, process simulation modelling can be used to study the catalytic HDO of 4-propylguaiacol with a very good validation when compared to CFD modelling and experimental results. This shows that the results obtained by incorporating the fluid flow conservation equations can be likened to the process simulation results for predicting the catalytic HDO of bio-oil in microreactors. Process modelling is often less arduous and has significantly shorter computational times when compared to CFD methodologies, thereby making process modelling an excellent tool to investigate the HDO of bio-oil in microreactors.

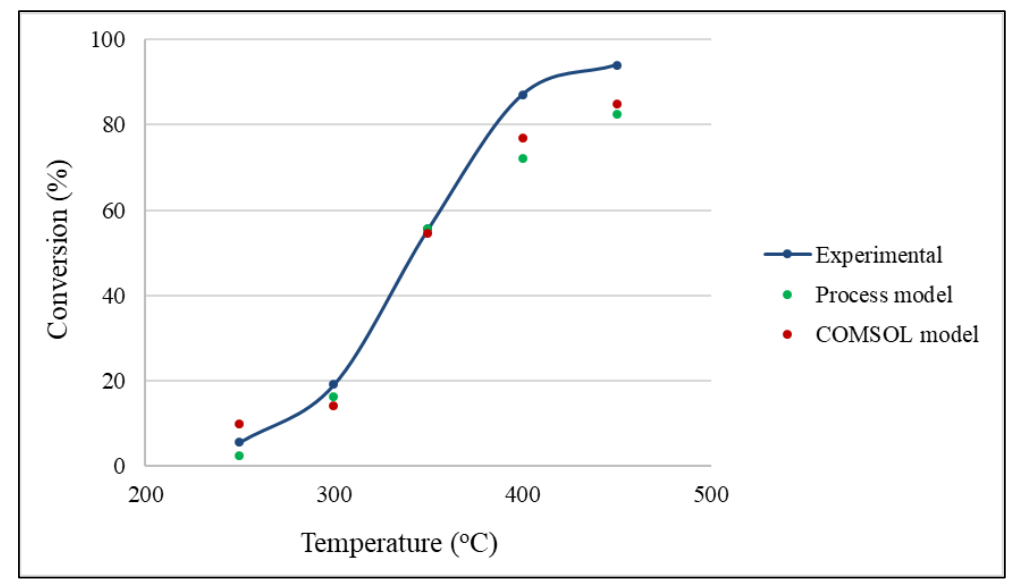

Figure 1. Comparison between the experimental and modelling findings. Reaction conditions: Pressure, 300 psig; gas phase, hydrogen; liquid phase, 4-propylguaiacol; liquid flow rate, $0.03 \mathrm{~mL} \cdot \mathrm{min}^{-1}$; gas flow rate, $0.09 \mathrm{~mL} \cdot \mathrm{min}^{-1}$.

From the results, it can be observed that further increases in temperature lead to a slight deviation in the results. This may be because of the secondary side reactions occurring during the process [23], which is not considered in this work due to the lack of kinetic data in open literature [8]. The compound 4-propylphenol is regarded as the sole product in this study because of its higher selectivity when compared to the other secondary products from this reaction such as 4-ethylphenol, 4-propylbenzene, phenols, and cresols.

Similar results were obtained by Leng et al. [24] investigating the HDO of three model compounds of bio-oil using a $\mathrm{NiFe} / \gamma-\mathrm{Al}_{2} \mathrm{O}_{3}$ catalyst. The results showed that the yield of ethyl oenanthate increased from approximately $15 \%$ to $97.9 \%$, with an increasing temperature from $300{ }^{\circ} \mathrm{C}$ to $400{ }^{\circ} \mathrm{C}$. On the other hand, the conversion of furfuryl alcohol and benzyl alcohol was greater than $85 \%$ at $300{ }^{\circ} \mathrm{C}$, and hence the effects of temperature were higher for ethyl oenanthate. The results obtained for the effects of temperature on ethyl oenanthate were consistent with the results of the current study. 


\subsection{Effects of Pressure}

The proposed model was used to investigate the effects of the inlet hydrogen pressure on the conversion of 4-propylguaiacol using a constant reactor temperature of $400{ }^{\circ} \mathrm{C}$. The range of pressures used was 240 to $480 \mathrm{psig}$, and the resultant conversions were observed. The results depicted in Figure 2 show that the conversion increases with increasing pressure. This is to be expected because as the pressure increases, the concentration of the reactants increases; hence, the conversion of 4-propylguaiacol is improved. The results obtained from the modelling were contrasted to the results obtained during the experimental work, and a good comparison between the data is observed. The experimental results show that at pressures greater than $400 \mathrm{psig}$, the conversion remains relatively stable [3]. This is because, at higher hydrogen pressures, there is the maximum adsorption of hydrogen on the surface of the catalyst particles.

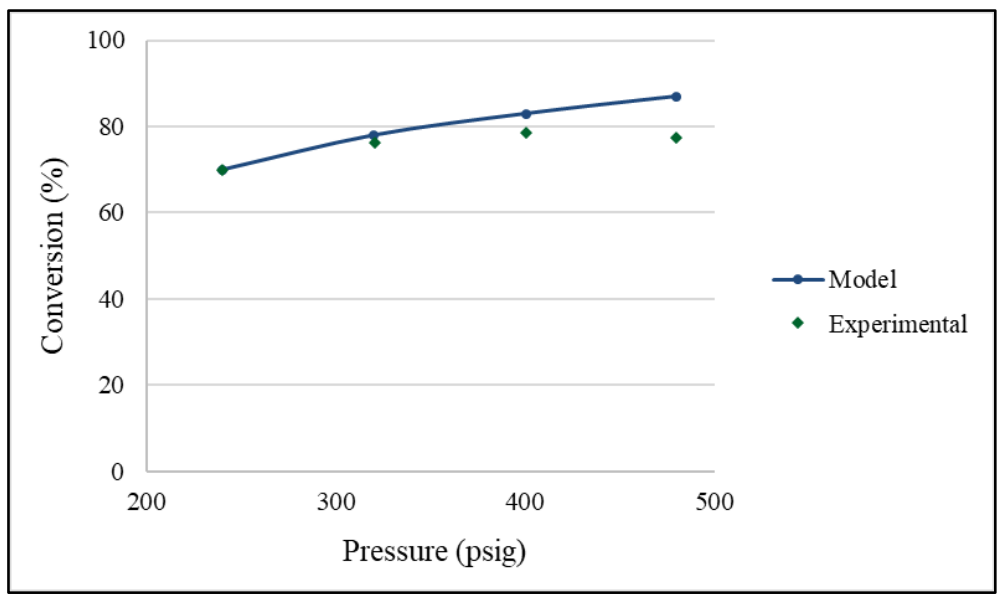

Figure 2. Effect of inlet hydrogen pressure on the conversion of 4-propylguaiacol. Reaction conditions: Temperature, $400{ }^{\circ} \mathrm{C}$; gas phase, hydrogen; liquid phase, 4-propylguaiacol; liquid flow rate, $0.03 \mathrm{~mL} \cdot \mathrm{min}^{-1}$; gas flow rate, $0.09 \mathrm{~mL} \cdot \mathrm{min}^{-1}$.

Similar results were obtained by Su-Ping [25], who studied the HDO of bio-oil derived from the fast pyrolysis of biomass. The catalyst used was a cobalt molybdate in an autoclave reactor. The effects of pressure were studied at a reaction temperature of $375{ }^{\circ} \mathrm{C}$ with a reaction time of $10 \mathrm{~min}$. The results showed that the hydrogen pressure had a small effect on the deoxygenation. This was due to the use of the tetralin solvent, which is a good hydrogen donor and can transfer active hydrogen and is not affected by changes in the hydrogen pressure. This is consistent with the experimental results in the current work.

Furthermore, Dimitriadis et al. [26] studied the HDO of lignocellulosic biomass derived pyrolysis oil over a NiMo $/ \mathrm{Al}_{2} \mathrm{O}_{3}$ catalyst. The results showed that higher pressures favoured the catalyst life expectancy. Furthermore, lower pressures resulted in lower deoxygenation, resulted in heavier molecules, and favoured the production of $\mathrm{CO}$. Higher reaction pressures led to higher reactant conversions. It was concluded that the longest catalyst activity was observed at the highest pressure of 1015 psig.

In addition, Patil et al. [27] studied the HDO of bio-oil using guaiacol as the model compound using a Ni-Mo/ $/ \mathrm{ZO}_{2}-\mathrm{Al}_{2} \mathrm{O}_{3}$ catalyst. The effects of pressure on the reaction were studied using three different pressures of 290, 435, and 580 psig, with a constant reaction temperature of $330{ }^{\circ} \mathrm{C}$ in tetralin. The results showed that the conversion of guaiacol and product yield increased with an increasing temperature from 290 to 435 psig. Any further increases in the pressure resulted in the conversion and product distribution remaining constant. Therefore, the optimal conditions were concluded to be a reaction temperature of $330{ }^{\circ} \mathrm{C}$ and a 435 psig hydrogen pressure. The findings from this study were consistent with the results observed in the current work. 


\subsection{Effects of Residence Time}

The effects of residence time on the conversion of 4-propylguaiacol was also investigated by varying the length of the reactor (catalyst loading) from 0.18 to $0.3 \mathrm{~m}$. The flow rates (liquid flow rate, $0.03 \mathrm{~mL} \cdot \mathrm{min}^{-1}$; gas flow rate, $\left.0.09 \mathrm{~mL} \cdot \mathrm{min}^{-1}\right)$, pressure $(300 \mathrm{psig}$ ), and temperature $\left(400^{\circ} \mathrm{C}\right)$ were kept constant to determine the effects of residence time on conversion. Figure 3 displays the results acquired where it is seen as the residence time increases, the conversion of 4-propylguaiacol is higher, as the reacting fluids spend a longer time in the reactor.

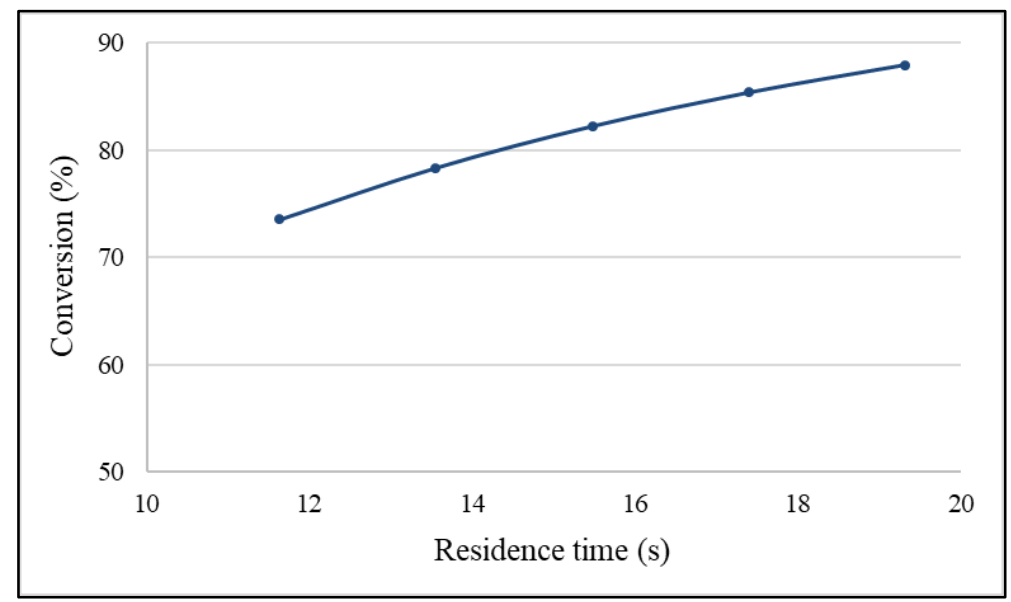

Figure 3. Effect of residence time on the conversion of 4-propylguaiacol. Reaction conditions: Temperature, $400{ }^{\circ} \mathrm{C}$; pressure, 300 psig; gas phase, hydrogen; liquid phase, 4-propylguaiacol; liquid flow rate, $0.03 \mathrm{~mL} \cdot \mathrm{min}^{-1}$; gas flow rate, $0.09 \mathrm{~mL} \cdot \mathrm{min}^{-1}$.

Su-Ping et al. [25] studied the effects of reaction time of the HDO of bio-oil derived from the fast pyrolysis of biomass. It was found that increasing the reaction time resulted in a decrease of the oxygen content in the liquid. At the beginning of the reaction, it was observed that the oxygen was removed much easily. Further increasing the time caused the deoxygenation rate to gradually decrease. Bio-oil contains various oxygen groups, as a result the deoxygenation of each oxygen group is different. This can explain why at the start of the reaction the oxygen was removed quickly. Nonetheless, the catalytic activity during deoxygenation was decreased.

Ausavasukhi et al. [28] investigated the HDO of m-cresol using a Ga-modified HMFI catalyst in a continuous flow fixed bed reactor. It was found that the conversion of the $\mathrm{m}$-cresol feed increased with increasing space time. Furthermore, the results showed that a significant increase in the yields of phenol and heavier phenolic compounds was observed when increasing the space time to approximately $6 \mathrm{~h}$. Increasing the time further resulted in a decrease of phenol and oxygenated compounds, whilst the yields of $\mathrm{C} 1$, C2-C6 hydrocarbons, benzene, toluene, and xylene gradually increase. Taghvaei et al. [29] investigated the HDO of guaiacol in a plasma reactor. The effects of the feed flow rate were studied using varying flow rates of 3,6 , and $9 \mathrm{~L} \cdot \mathrm{h}^{-1}$. The results showed that increasing the feed flow rate led to a decreased residence time which resulted in a decrease of the guaiacol conversion. The results obtained from the study are comparable to the trend observed in the current work.

Figure 4 shows how the vapour phase mass composition of 4-propylguaiacol and 4-propylphenol vary along the length of the reactor, respectively. The results displayed show that the vapour phase mass composition of the reactant 4-propylguaiacol decreases along the length of the microreactor, and the vapour phase mass composition of the product 4-propylphenol increases along the microreactor. This is the expected result because as the reaction rate declines along the length of the microreactor, the amount of 4-propylguaiacol consumed also increases. As a result, a greater amount of 4-propylphenol is produced. 


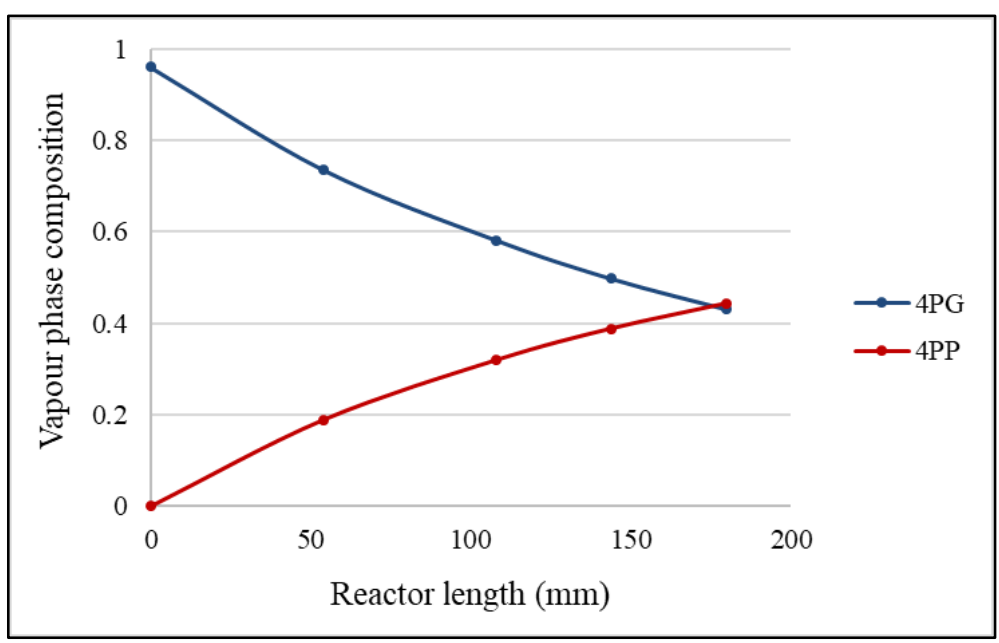

Figure 4. Vapor phase mass composition along the microreactor for 4-propylguaiacol and 4propylphenol. Reaction conditions: Temperature, $400{ }^{\circ} \mathrm{C}$; pressure, 300 psig; gas phase, hydrogen; liquid phase, 4-propylguaiacol; liquid flow rate, $0.03 \mathrm{~mL} \cdot \mathrm{min}^{-1}$; gas flow rate, $0.09 \mathrm{~mL} \cdot \mathrm{min}^{-1}$.

\subsection{Effects of Adiabatic Conditions}

The microreactor configuration was then altered to operate adiabatically (i.e., the plug flow microreactor was well insulated to minimise the effects of heat transfer (no heat exchange with the environment)), and any temperature variations from the initial inlet conditions will be due to the heat released from the reactions only. Subsequently, the conversion of 4-propylguaiacol obtained, using this configuration, will differ from that of the isothermal design. Table 1 illustrates the results achieved for the adiabatic case. It can be noticed that when the temperature effects of the reaction are considered, the conversion is slightly higher than that of isothermal conditions.

Table 1. Results obtained for isothermal and adiabatic reactor conditions.

\begin{tabular}{cc}
\hline Reactor Conditions & Conversion (\%) \\
\hline Isothermal $\left(400^{\circ} \mathrm{C}\right)$ & 55.60 \\
\hline Adiabatic & 66.10 \\
\hline
\end{tabular}

Figure 5 shows how the temperature of the reaction varies with the length of the microreactor. From the graph, it can be observed that the reaction is exothermic; as the length of the reactor increases, the temperature also increases. Figure 6 shows how the duty varies along the length of the microreactor under isothermal conditions. The results show that as the microreactor length increases, the duty decreases. During isothermal operating conditions, a larger amount of cooling will be required as the reaction progresses along the plug flow microreactor. 


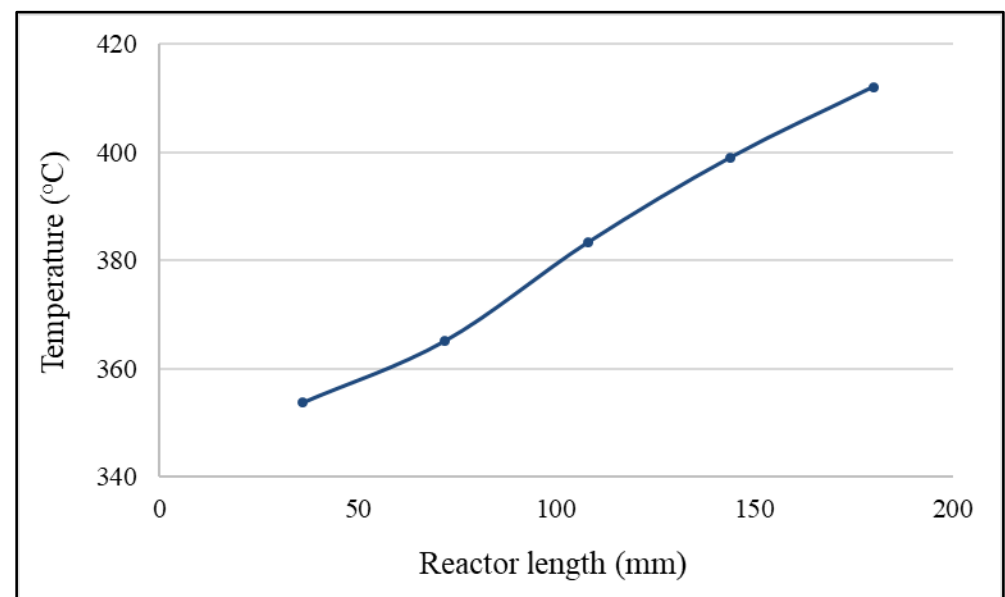

Figure 5. Temperature variations along the reactor length. Reaction conditions: Pressure, 300 psig; gas phase, hydrogen; liquid phase, 4-propylguaiacol; liquid flow rate, $0.03 \mathrm{~mL} \cdot \mathrm{min}^{-1}$; gas flow rate, $0.09 \mathrm{~mL} \cdot \mathrm{min}^{-1}$.

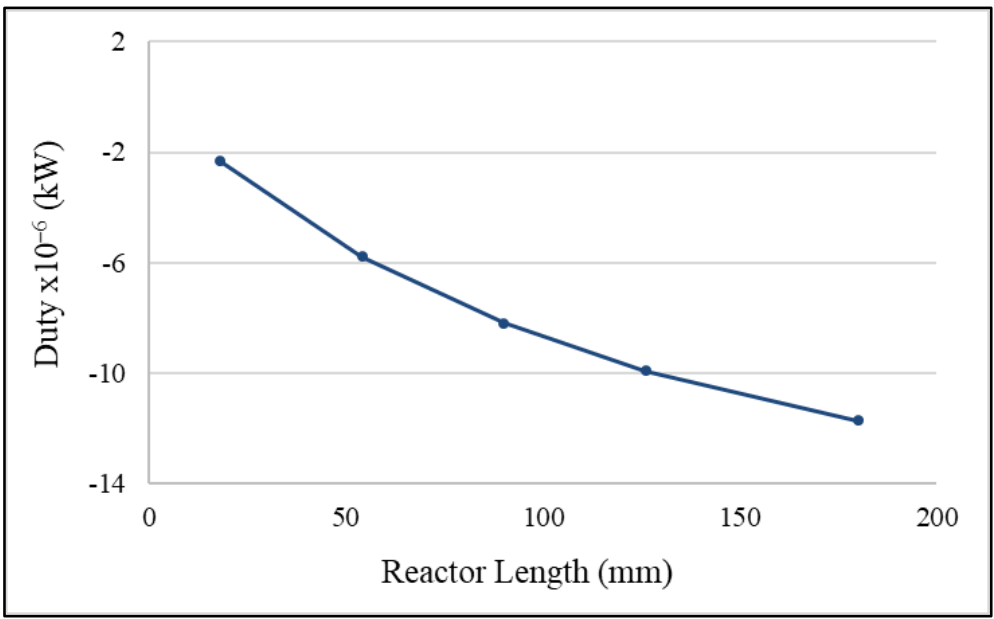

Figure 6. Duty variations along the reactor length. Reaction conditions: Pressure, 300 psig; gas phase, hydrogen; liquid phase 4-propylguaiacol; liquid flow rate, $0.03 \mathrm{~mL} \cdot \mathrm{min}^{-1}$; gas flow rate, $0.09 \mathrm{~mL} \cdot \mathrm{min}^{-1}$.

\subsection{Effects of Equation of State}

To examine the effect of the equation of state, the Peng-Robinson equation was changed to the Redlich-Kwong-Soave equation of state during the process simulation modelling. Figure 7 shows the comparisons between the two equations of state used. The results show that there is not much variation in conversion with the different methods used rendering it irrelevant. However, despite the lack of variation in results obtained with both equations of state, the Peng-Robinson method was selected for the study. This was due to the fact that the Peng-Robinson equation has demonstrated superiority over the RedlichKwong-Soave equation when predicting subcritical properties such as vapor pressure and enthalpies of vaporisation [30]. Nonetheless, both equations of state are suitable to be used with the reactor model produced. In addition, similar results are obtained when other suitable equations of state are used to solve the model in the current work. 


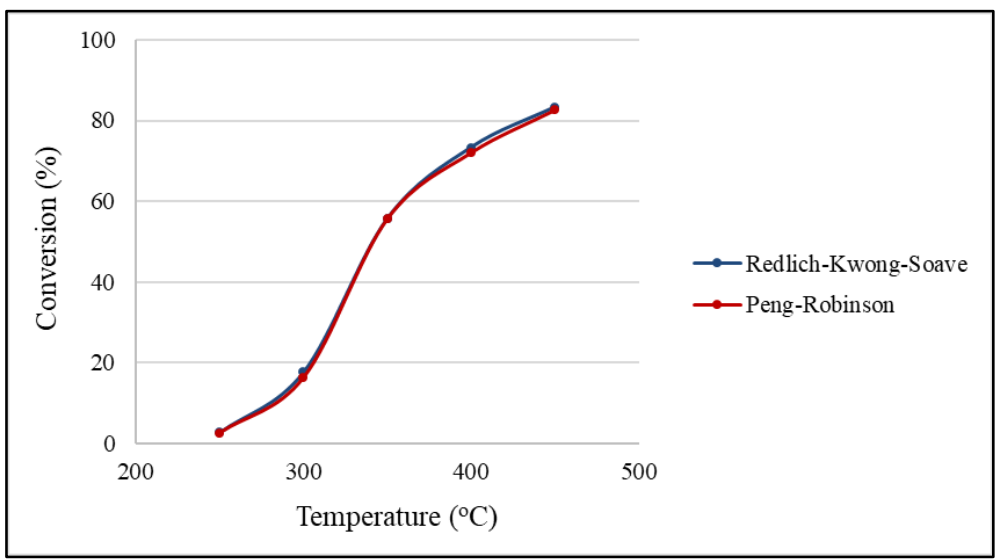

Figure 7. Effects of different equations of state. Reaction conditions: Temperature, $400{ }^{\circ} \mathrm{C}$, pressure, 300 psig; gas phase, hydrogen; liquid phase, 4-propylguaiacol; liquid flow rate, $0.03 \mathrm{~mL} \cdot \mathrm{min}^{-1}$; gas flow rate, $0.09 \mathrm{~mL} \cdot \mathrm{min}^{-1}$.

\section{Modelling Methodology}

\subsection{Process Description and Mathematical Formulae}

As the simulation results are based on experimental work from Joshi et al. [3], we have replicated the experimental reactor and process conditions from the experimental work. Further details of the experimental work and schematic diagram of the experimental set up can be found in [3]. The process operates under isothermal and steady-state conditions. The equation of state selected for the model is Peng-Robinson, and the model is assumed to be pseudo-homogeneous. However, the vapor-liquid equilibrium is still accounted for by the Aspen Plus simulation exercises. The type of reactor is assumed to be a pseudo homogeneous plug flow microreactor with dimensions as per the following: length $=180 \mathrm{~mm}$, and internal diameter $=0.762 \mathrm{~mm}$ (the PFR block was selected in ASPEN Plus to represent this). The concentration of 4-propylguaiacol is $1.1 \mathrm{M}$ in pure hexane, the specified liquid flow rates include the hexane. The catalyst utilised for this study is a pre-sulfided $\mathrm{NiMo} / \mathrm{Al}_{2} \mathrm{O}_{3}$, and the mass of the catalyst is $0.026-0.19 \mathrm{~g}$. The bed porosity $(\varepsilon)$ is 0.3 , and the catalyst particle density is $580 \mathrm{~kg} \mathrm{~m}^{-3}$. The pressure drop of the microreactor varied between 10 to 29 psig along its body depending on the length of the microreactor [3].

Figure 8 displays a schematic diagram of which the process simulation model is based.

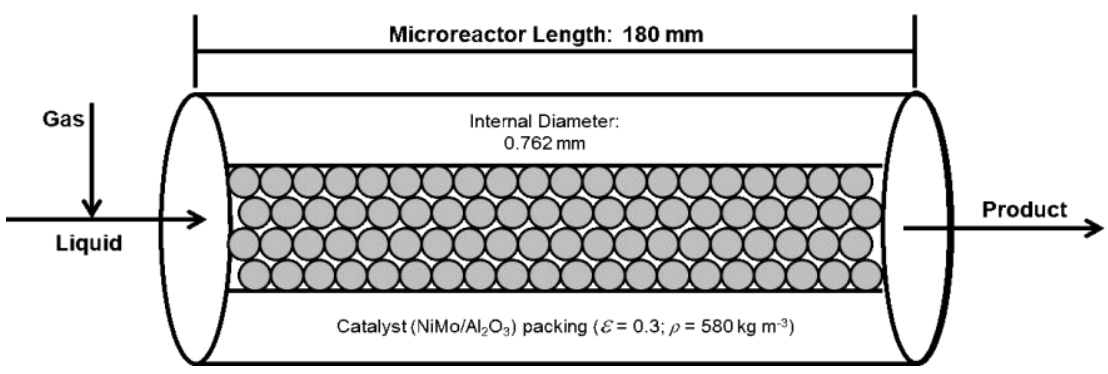

Figure 8. Schematic of the microreactor used for the implementation of the mathematical model.

Larger scale packed bed reactors will require the use of larger sized catalyst particles, and this can lead to pore diffusion limitations within the reactor. As a result, lower reactant conversions are observed [31]. Using smaller sized catalyst particles can diminish this problem. However, it may lead to excessive pressure drops within these larger reactors. Microreactors can eliminate the problem of large pressure drops due to their small size, as well as enhancing the mass transfer.

For the wide variety of catalytic surface reactions, the Langmuir-Hinshelwood mechanism is often regarded as preferred mechanism [32]. The Langmuir-Hinshelwood mechanism is based on a reaction of two types of molecules proceeding on a surface in which 
both molecules are adsorbed at the same surface adsorption sites. The surface reaction is regarded as the rate determining step [33]. The LHHW expression of catalyst kinetics is used to calculate the rate of reaction and was utilized in Aspen Plus to model the microreactor. This kinetic model is comprised of a kinetic factor, a driving force expression, and an adsorption term. The general LHHW expression is given by [34]:

$$
r=\frac{(\text { kinetic factor }) \text { (driving force expression) }}{(\text { adsorption term })}
$$

The kinetic factor can be expressed as: $k T^{n} e^{\frac{-E a}{R T}}$ following the Arrhenius first order equation, where $k$ is the pre-exponential factor in the Arrhenius expression, $E_{a}$ is the activation energy $\left(\mathrm{J} \cdot \mathrm{mol}^{-1}\right)$, and a temperature dependence can be expressed through the exponent $n$. The driving force expression describes the number of the reactants in the fluid phase, each with their own reaction order considering the forward and backward (reversible) reactions. The driving force expression is depicted as follows:

$$
k_{1} \prod C_{i}^{\alpha_{i}}-k_{2} \prod C_{j}^{\beta_{j}}
$$

where, $k_{1}$ and $k_{2}$ represent equilibrium constants. The adsorption term is expressed as:

$$
\left(\sum K_{i}\left(\prod C_{j}^{v_{j}}\right)\right)^{m}
$$

where, $K_{i}$ represents the adsorption constant of each chemical species, $i$ and $j$ represent the chemical species. The basis of concentration for the driving force and the adsorption terms is the fugacity raised to the power of the concentration for the forward and backward reactions. It is imperative to express the equilibrium and adsorption constants in the subsequent format to calculate their reliance on temperature:

$$
\ln (K)=A+\frac{B}{T}+C \ln (T)+D T
$$

where, $A, B, C$, and $D$ represent constants. The Peng-Robinson equation of state is highly suited for handling systems, which contain hydrocarbons, water, and air [35]. The equation implemented was in the form shown below as [35]:

$$
\begin{gathered}
P=\frac{R T}{v-b}-\frac{a(T)}{v(v+b)+b(v-b)} \\
b=0.07780 \frac{R T_{c}}{P_{c}} \\
a(T)=a\left(T_{c}\right) \cdot \alpha\left(T_{R}, \omega\right) \\
a\left(T_{c}\right)=0.45724 \frac{R^{2} T_{c}^{2}}{P_{c}} \\
Z_{c}=0.307 \\
\alpha^{\frac{1}{2}}\left(T_{R}, \omega\right)=1+k\left(1-T_{R}^{\frac{1}{2}}\right) \\
k=037464+1.54226 \omega-0.26992 \omega^{2}
\end{gathered}
$$

where, $a$ is the attraction parameter, $b$ is the van der Waals covolume, $v$ is the molar volume $\left(\mathrm{m}^{3} \cdot \mathrm{mol}^{-1}\right), R$ is the gas constant $\left(\mathrm{J} \cdot \mathrm{mol}^{-1} \mathrm{~K}^{-1}\right)$, and $T c$ and $P c$ are the critical temperature $(\mathrm{K})$ and pressure $(\mathrm{Pa})$, respectively. $Z$ is the compressibility factor, $w$ is the acentric factor, and $k$ is the characteristic constant. 
The reactor energy balance, coupled with the material balance, can determine the heating or cooling requirements. The energy balance for the packed bed reactor can be given as:

$$
\frac{d T}{d W}=\frac{r_{A}^{\prime} \Delta H_{R x}(T)-\frac{U a}{\rho_{b}}\left(T-T_{a}\right)}{\sum F_{i} C_{P i}}
$$

where $T$ is the reaction temperature, $r_{A}^{\prime}$ is the rate of reaction $\left(\mathrm{mol} \cdot \mathrm{m}^{-3} \mathrm{~s}^{-1}\right), \Delta H_{R X}$ is the constant heat of reaction $\left(\mathrm{Kj} \cdot \mathrm{mol}^{-1}\right), U$ is the overall heat transfer coefficient $\left(\mathrm{W} \cdot \mathrm{m}^{-2} \mathrm{~K}^{-1}\right)$, $T_{a}$ is the ambient temperature, $C_{p i}$ is the average heat capacity of species $i\left(\mathrm{~J} \cdot \mathrm{K}^{-1}\right), a$ is the heat exchange area for the packed bed reactor $\left(\mathrm{m}^{2}\right), \rho_{b}$ is the is the bulk density of the catalyst $\left(\mathrm{kg} \cdot \mathrm{m}^{-3}\right)$, and $\mathrm{Fi}$ is the molar flow rate $\left(\mathrm{mol} \cdot \mathrm{s}^{-1}\right)$ [36].

\subsection{Reaction Pathway and Kinetics}

Figure 9 displays the single reaction utilised for the process modelling for the HDO reaction. The experimental result for the reaction suggests that the reaction kinetics are determined by the surface reaction step for competitive reaction with non-dissociative adsorption of hydrogen. This was used in this study and the reaction kinetics are defined by using the LHHW kinetics thus:

$$
-r^{\prime}{ }_{4 P G}=\frac{k\left(K_{H 2}{ }^{e q l} C_{H 2}\right)\left(K_{4 P G}{ }^{e q l} C_{4 P G}\right)}{\left(1+K_{H 2}{ }^{e q l} C_{H 2}\right)\left(1+K_{4 P G}{ }^{e q l} C_{4 P G}\right)}
$$

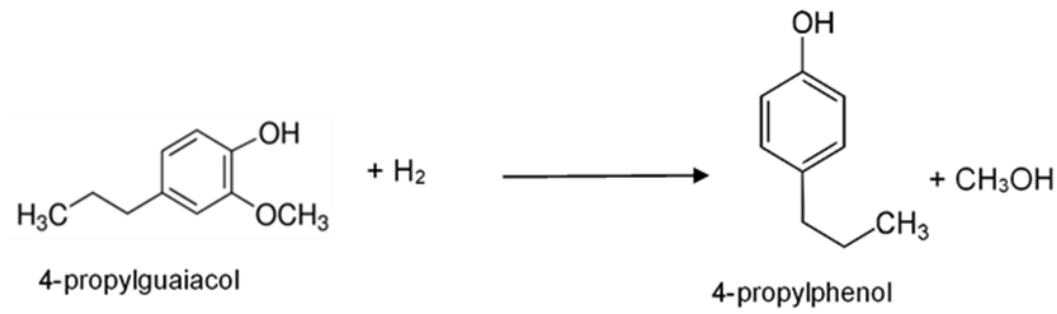

Figure 9. Reaction pathway considered for the catalytic HDO of 4-Propylguaiacol to 4-propylphenol.

The rate expression suggests that the reaction can be considered a pseudo-first order with regards to hydrogen and 4-propylguaiacol. The kinetic constants from rate equation derived from the published experimental results are listed in Table 2, which were used to validate the model described previously in this work. The pre-exponential factors, activation energy and heats of adsorption for the reaction are listed in Table 3.

Table 2. Numerical parameters and rate constants used for the described process simulation model [3].

\begin{tabular}{|c|c|c|c|c|}
\hline $\mathrm{T}\left({ }^{\circ} \mathrm{C}\right)$ & $\mathrm{k}\left(\mathrm{mol} \cdot \mathrm{g}^{-1} \mathrm{~h}^{-1}\right)$ & K4PG (L· mol-1) & KH2 $\left(\mathrm{L} \cdot \mathrm{mol}^{-1}\right)$ & $\mathbf{R}^{2}$ \\
\hline 250 & $22.21 \pm 0.77$ & $0.02 \pm 0.002$ & $0.3 \pm 0.004$ & 0.97 \\
\hline 300 & $41.40 \pm 4.21$ & $0.1 \pm 0.01$ & $0.1 \pm 0.01$ & 0.96 \\
\hline 350 & $77.78 \pm 0.01$ & $0.6 \pm\left(9.7 \times 10^{-5}\right)$ & $0.02 \pm\left(1.6 \times 10^{-6}\right)$ & 0.96 \\
\hline
\end{tabular}
Reproduced from Ref. [8] with permission from the Royal Society of Chemistry. 
Table 3. Reaction Pre-exponential factors, activation energy and heats of adsorption [3]. Reproduced from Ref. [8] with permission from the Royal Society of Chemistry.

\begin{tabular}{cc}
\hline \multicolumn{1}{c}{ Intrinsic Constant } & Value \\
\hline \multicolumn{2}{c}{ Pre-exponential factors } \\
\hline$k_{0}\left(\times 10^{4} \mathrm{~mol} \cdot \mathrm{g}^{-1} \mathrm{~h}^{-1}\right)$ & $5.29 \pm 0.66$ \\
\hline$K_{4-\text { Propylguaiacol }, 0}\left(\times 10^{7} \mathrm{~L} \cdot \mathrm{mol}^{-1}\right)$ & $2.750 \pm 0.14$ \\
\hline$K_{H 2,0}\left(\times 10^{-8} \mathrm{~L} \cdot \mathrm{mol}^{-1}\right)$ & $1.6 \pm 0.13$ \\
\hline Activation energies and heats of adsorption $\left.^{-1}\right)$ & $33.86 \pm 2.70$ \\
\hline$E_{a}\left(\mathrm{~kJ} \cdot \mathrm{mol}^{-1}\right)$ & $91.85 \pm 2.69$ \\
\hline$\Delta H_{4-\text { Propylguaiacol }}\left(\mathrm{kJ} \cdot \mathrm{mol}^{-1}\right)$ & $-72.69 \pm 2.63$ \\
\hline$\Delta H_{H 2}\left(\mathrm{~kJ} \cdot \mathrm{mol}^{-1}\right)$ &
\end{tabular}

\section{Conclusions}

The catalytic HDO of bio-oil has been theoretically investigated in this study by selecting 4-propylguaicol as the model compound in a microreactor. The HDO of bio-oil in microreactors is mainly studied on an experimental basis, so there is great potential to perform these studies on a theoretical basis. Experimental work can often be regarded as time consuming and costly, whereas theoretical modelling exercises can offer detailed information on reaction parameters such as temperature, pressure, and concentration, within the reactor with minimal effort.

The results obtained from the process modelling performed in Aspen Plus for the catalytic HDO of 4-propylguaiacol to 4-propylphenol show a very good agreement with the experimental results utilised from literature, as well as the results achieved from the CFD study. The results show that the conversion of 4-propylguaiacol increases as the temperature increases. The deviations in the model and experimental results are observed for reactor temperatures greater than $350{ }^{\circ} \mathrm{C}$. The discrepancy between these results is due to the \% yield of other major reaction products which are not considered in this work, as the compound 4-propylguaiacol has been solely chosen for investigation. From the qualitative analysis of the experimental results, it is deduced that the process simulation model agrees significantly well with the experimental data. Further parametric studies revealed that the conversion is enhanced when pressure and residence time are increased, as well as when adiabatic conditions are used. The parametric studies performed in this study revealed that the highest conversion of 4-propylguaiacol is achieved at a reaction temperature of $450{ }^{\circ} \mathrm{C}$, and pressure 500 psig.

The process simulation software, Aspen Plus, provides a good foundation based on mass and energy balances, mass, and heat transfer, as well as reaction modelling and phase equilibria to depict the HDO of 4-propylguaiacol in microreactors. Building on the Aspen Plus capabilities we developed a simple innovative reactor process model incorporating phase equilibrium calculations. Both the CFD and process modelling exercises have generated similar results which suggests that both methods could be used to study the catalytic HDO of bio-oil in microreactors. Nonetheless, process modelling can potentially offer less computational times and does not require as much computing power. To conclude, this model can be utilized to present the HDO of other compounds present in bio-oils derived from pyrolysis. Future exploitation of our results should be directed towards enhancing fuel output by means of scaling up the microreactors, and their potential use for offshore fuel production.

Author Contributions: Conceptualization, G.M. and A.C.; Formal analysis, S.H., E.A. and S.M.A.-S.; Investigation, S.H. and S.M.; Methodology, S.M.A.-S., G.M. and A.C.; Software, S.H., S.M.; Supervision, G.M. and A.C.; Writing-original draft, S.H.; Writing—review \& editing, S.H., E.A., S.M.A.-S., G.M. and A.C. All authors have read and agreed to the published version of the manuscript. 
Funding: This research received no external funding.

Acknowledgments: The authors would like to thank London South Bank University, School of Engineering for the PhD fund that supports the work of Sanaa Hafeez.

Conflicts of Interest: The authors declare no conflict of interest.

\section{Nomenclature}

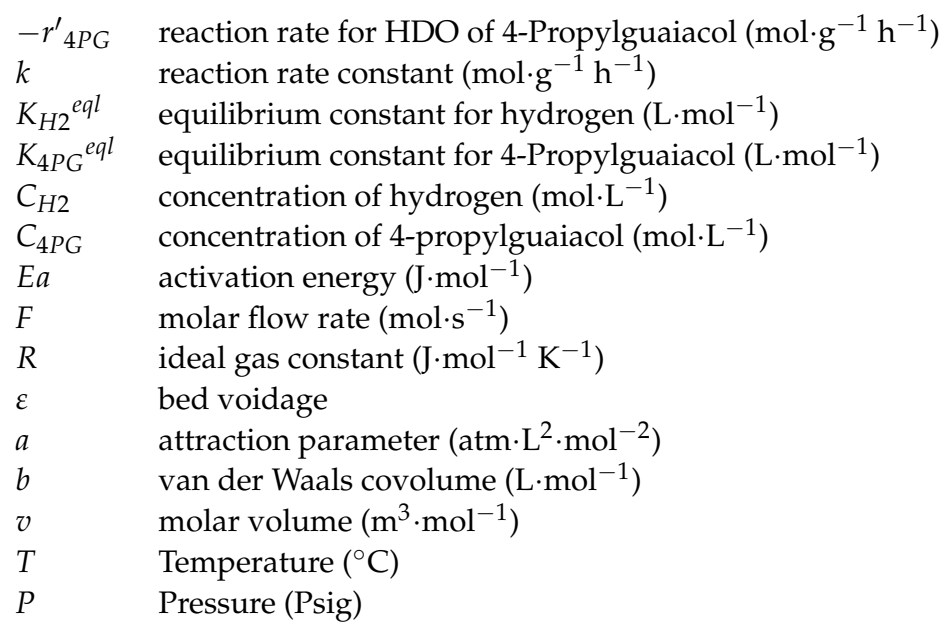

\section{References}

1. Hafeez, S.; Pallari, E.; Manos, G.; Constantinou, A. Catalytic conversion and chemical recovery. In Plastics to Energy; Elsevier: Amsterdam, The Netherlands, 2019; pp. 147-172.

2. Hallale, N.; Liu, F. Refinery hydrogen management for clean fuels production. Adv. Environ. Res. 2001, 6, 81-98. [CrossRef]

3. Joshi, N.; Lawal, A. Hydrodeoxygenation of 4-propylguaiacol (2-methoxy-4-propylphenol) in a microreactor: Performance and kinetic studies. Ind. Eng. Chem. Res. 2013, 52, 4049-4058. [CrossRef]

4. Bridgwater, A.; Meier, D.; Radlein, D. An overview of fast pyrolysis of biomass. Org. Geochem. 1999, 30, 1479-1493. [CrossRef]

5. Bridgwater, A.V. Review of fast pyrolysis of biomass and product upgrading. Biomass Bioenergy 2012, 38, 68-94. [CrossRef]

6. Nimmanwudipong, T.; Runnebaum, R.C.; Block, D.E.; Gates, B.C. Catalytic reactions of guaiacol: Reaction network and evidence of oxygen removal in reactions with hydrogen. Catal. Lett. 2011, 141, 779-783. [CrossRef]

7. Lee, H.; Kim, Y.-M.; Lee, I.-G.; Jeon, J.-K.; Jung, S.-C.; Chung, J.D.; Choi, W.G.; Park, Y.-K. Recent advances in the catalytic hydrodeoxygenation of bio-oil. Korean J. Chem. Eng. 2016, 33, 3299-3315. [CrossRef]

8. Hafeez, S.; Aristodemou, E.; Manos, G.; Al-Salem, S.; Constantinou, A. Computational fluid dynamics (CFD) and reaction modelling study of bio-oil catalytic hydrodeoxygenation in microreactors. React. Chem. Eng. 2020, 5, 1083-1092. [CrossRef]

9. Shu, R.; Lin, B.; Zhang, J.; Wang, C.; Yang, Z.; Chen, Y. Efficient catalytic hydrodeoxygenation of phenolic compounds and bio-oil over highly dispersed $\mathrm{Ru} / \mathrm{TiO}_{2}$. Fuel Process. Technol. 2019, 184, 12-18. [CrossRef]

10. Zerva, C.; Karakoulia, S.A.; Kalogiannis, K.G.; Margellou, A.; Iliopoulou, E.F.; Lappas, A.A.; Papayannakos, N.; Triantafyllidis, K.S. Hydrodeoxygenation of phenol and biomass fast pyrolysis oil (bio-oil) over $\mathrm{Ni} / \mathrm{WO}_{3}-\mathrm{ZrO}_{2}$ catalyst. Catal. Today 2021, 366, 57-67. [CrossRef]

11. Tran, Q.K.; Ly, H.V.; Kwon, B.; Kim, S.-S.; Kim, J. Catalytic hydrodeoxygenation of guaiacol as a model compound of woody bio-oil over $\mathrm{Fe} / \mathrm{AC}$ and $\mathrm{Ni} / \gamma-\mathrm{Al}_{2} \mathrm{O}_{3}$ catalysts. Renew. Energy 2021, 173, 886-895. [CrossRef]

12. Lv, Q.; Yue, H.; Xu, Q.; Zhang, C.; Zhang, R. Quantifying the exergetic performance of bio-fuel production process including fast pyrolysis and bio-oil hydrodeoxygenation. J. Renew. Sustain. Energy 2018, 10, 043107. [CrossRef]

13. Bagnato, G.; Sanna, A. Process and techno-economic analysis for fuel and chemical production by hydrodeoxygenation of bio-oil. Catalysts 2019, 9, 1021. [CrossRef]

14. Shemfe, M.B.; Fidalgo, B.; Gu, S. Heat integration for bio-oil hydroprocessing coupled with aqueous phase steam reforming. Chem. Eng. Res. Des. 2016, 107, 73-80. [CrossRef]

15. Hafeez, S.; Manos, G.; Al-Salem, S.; Aristodemou, E.; Constantinou, A. Liquid fuel synthesis in microreactors. React. Chem. Eng. 2018, 3, 414-432. [CrossRef]

16. Constantinou, A.; Ghiotto, F.; Lam, K.F.; Gavriilidis, A. Stripping of acetone from water with microfabricated and membrane gas-liquid contactors. Analyst 2014, 139, 266-272. [CrossRef]

17. Sun, X.; Constantinou, A.; Gavriilidis, A. Stripping of acetone from isopropanol solution with membrane and mesh gas-liquid contactors. Chem. Eng. Process. Process Intensif. 2011, 50, 991-997. [CrossRef] 
18. Todić, B.; Ordomsky, V.V.; Nikačević, N.M.; Khodakov, A.Y.; Bukur, D.B. Opportunities for intensification of Fischer-Tropsch synthesis through reduced formation of methane over cobalt catalysts in microreactors. Catal. Sci. Technol. 2015, 5, $1400-1411$. [CrossRef]

19. Fortunate, O.; Kishore, N. Computational Fluid Dynamics Investigation on Catalytic Hydrodeoxygenation of a Bio-Oil Model Compound in a Fluidized Bed Reactor. J. Therm. Sci. Eng. Appl. 2021, 13, 061018. [CrossRef]

20. Gollakota, A.R.; Subramanyam, M.D.; Kishore, N.; Gu, S. CFD simulations on the effect of catalysts on the hydrodeoxygenation of bio-oil. RSC Adv. 2015, 5, 41855-41866. [CrossRef]

21. Subramanyam, M.D.; Gollakota, A.R.; Kishore, N. CFD simulations of catalytic hydrodeoxygenation of bio-oil using $\mathrm{Pt} / \mathrm{Al}_{2} \mathrm{O}_{3}$ in a fixed bed reactor. RSC Adv. 2015, 5, 90354-90366. [CrossRef]

22. $\mathrm{Ng}$, K.S.; Martinez-Hernandez, E. Techno-economic assessment of an integrated bio-oil steam reforming and hydrodeoxygenation system for polygeneration of hydrogen, chemicals, and combined heat and power production. In Towards Sustainable Chemical Processes; Elsevier: Amsterdam, The Netherlands, 2020; pp. 69-98.

23. Nowakowska, M.; Herbinet, O.; Dufour, A.; Glaude, P.-A. Kinetic study of the pyrolysis and oxidation of guaiacol. J. Phys. Chem. A 2018, 122, 7894-7909. [CrossRef] [PubMed]

24. Leng, S.; Wang, X.; He, X.; Liu, L.; Zhong, X.; Zhuang, G.; Wang, J.-G. NiFe $/ \gamma-\mathrm{Al}_{2} \mathrm{O}_{3}$ : A universal catalyst for the hydrodeoxygenation of bio-oil and its model compounds. Catal. Commun. 2013, 41,34-37. [CrossRef]

25. Su-Ping, Z. Study of hydrodeoxygenation of bio-oil from the fast pyrolysis of biomass. Energy Sources 2003, 25, 57-65. [CrossRef]

26. Dimitriadis, A.; Chrysikou, L.P.; Meletidis, G.; Terzis, G.; Auersvald, M.; Kubička, D.; Bezergianni, S. Bio-based refinery intermediate production via hydrodeoxygenation of fast pyrolysis bio-oil. Renew. Energy 2021, 168, 593-605. [CrossRef]

27. Patil, M.L.; Lali, A.M.; Dalai, A.K. Catalytic hydrodeoxygenation of bio-oil model compound for production of fuel grade oil. Asia Pac. J. Chem. Eng. 2019, 14, e2317. [CrossRef]

28. Ausavasukhi, A.; Huang, Y.; To, A.T.; Sooknoi, T.; Resasco, D.E. Hydrodeoxygenation of m-cresol over gallium-modified beta zeolite catalysts. J. Catal. 2012, 290, 90-100. [CrossRef]

29. Taghvaei, H.; Rahimpour, M.R. Catalytic hydrodeoxygenation of bio-oil using in situ generated hydrogen in plasma reactor: Effects of allumina supported catalysts and plasma parameters. Process Saf. Environ. Prot. 2019, 121, 221-228. [CrossRef]

30. Ghanbari, M.; Ahmadi, M.; Lashanizadegan, A. A comparison between Peng-Robinson and Soave-Redlich-Kwong cubic equations of state from modification perspective. Cryogenics 2017, 84, 13-19. [CrossRef]

31. Hafeez, S.; Aristodemou, E.; Manos, G.; Al-Salem, S.; Constantinou, A. Modelling of packed bed and coated wall microreactors for methanol steam reforming for hydrogen production. RSC Adv. 2020, 10, 41680-41692. [CrossRef]

32. Kumar, K.V.; Porkodi, K.; Rocha, F. Langmuir-Hinshelwood kinetics-A theoretical study. Catal. Commun. 2008, 9, 82-84. [CrossRef]

33. Ohtani, B. Photocatalysis by inorganic solid materials: Revisiting its definition, concepts, and experimental procedures. Adv. Inorg. Chem. 2011, 63, 395-430. [CrossRef]

34. Al-Malah, K.I. Aspen Plus: Chemical Engineering Applications; John Wiley \& Sons: Hoboken, NJ, USA, 2016.

35. Peng, D.-Y.; Robinson, D.B. A new two-constant equation of state. Ind. Eng. Chem. Fundam. 1976, 15, 59-64. [CrossRef]

36. Fogler, H. Chapter 10: Catalysis and Catalytic Reactors. Elem. Chem. React. Eng. 2016, 5, 454-456. 